\title{
Commemorative Naming in the United States
}

\section{Introduction}

Naming is a basic human tendency; it allows us to perceive the distinct identities of people and places and conveys those characteristics that make them unique. The name of a geographic feature can describe spectacular physical attributes (such as the Grand Canyon or Half Dome in Yosemite National Park), indicate cultural or historical significance (such as Washington Crossing on the Delaware River), or commemorate a worthy individual (such as the Hudson River, named for Henry Hudson, the explorer). Names have many different origins, and regardless of the type of name, they give us a greater familiarity with our surroundings and a sense of belonging to our environment.

Naming rivers, mountains, and valleys after individuals was one way settlers marked the land; it signified their lives on these lands were important and, in addition to being a point of reference, usually satisfied the need for stability and enhanced the general concept of sense of place. Even today, naming geographic features after individuals helps us to recognize their special achievements and contributions to the physical or cultural landscape. However, what may be most significant about the present commemorative naming decisions is their permanence. It is important for us to realize that the commemorative names assigned today may last for centuries.

\section{The U.S. Board on Geographic Names}

President Benjamin Harrison created the U.S. Board on Geographic Names by Executive order in 1890, and the Board was restructured by Public Law in 1947. The Board's mission is to encourage uniform name usage to eliminate confusion and to promote consistency in the adjudication of name decisions. The need for such a Board became evident as the American population expanded and

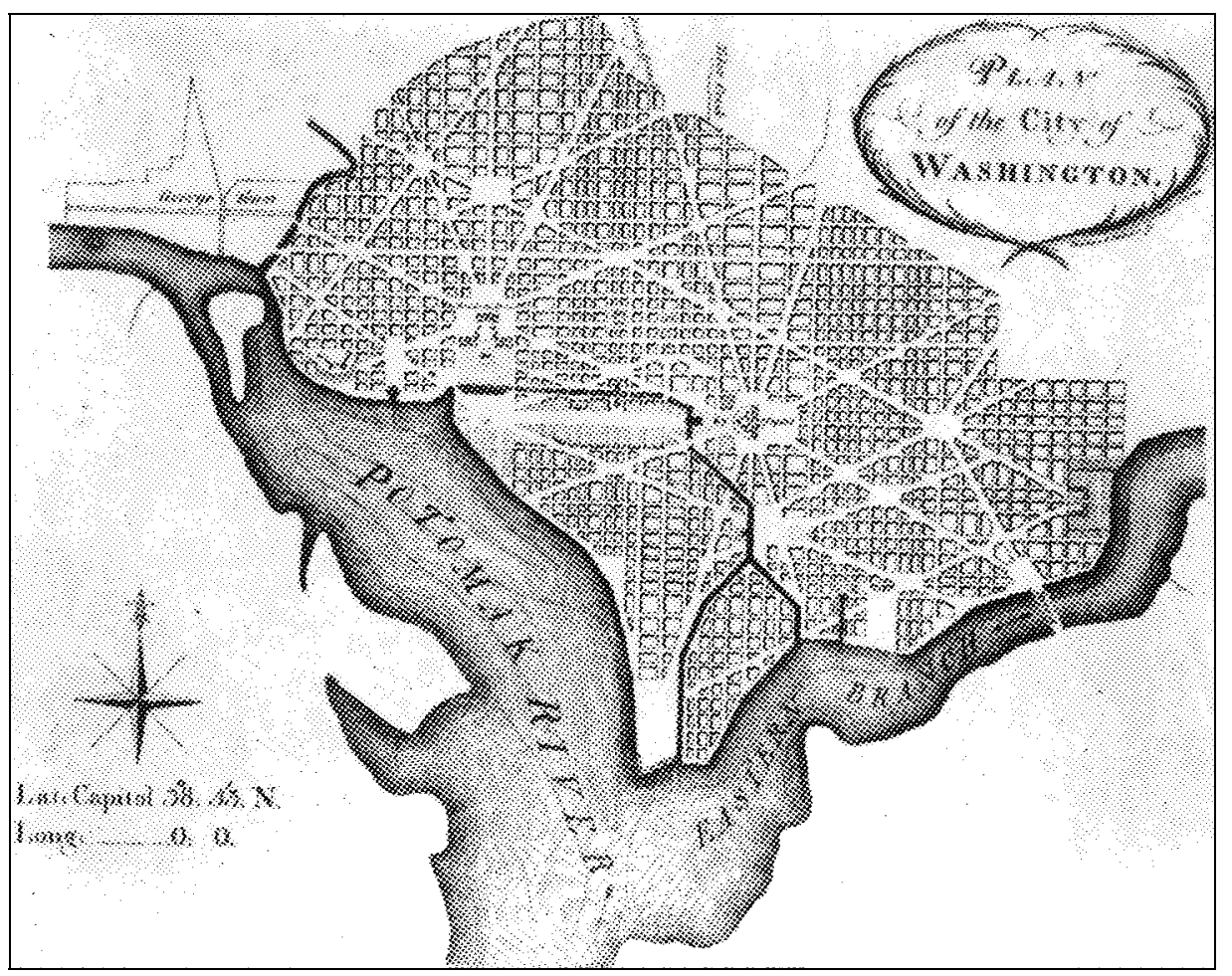

Commemorative naming recognizes individuals who have made a significant contribution to a specific geographic area or feature. The name of the city of Washington, D.C., depicted in this 1792 map, commemorates the first President of the United States, George Washington.

features were given multiple names. Printed materials such as maps, journals, and newspapers conveyed different usage, and simply finding out what a feature was called or where it was located depended on to whom one spoke or what source was used. Today the Board, which is composed of representatives from many Federal agencies, continues to promote uniform name usage by standardizing the spelling and application of geographic names on all official maps and publications.

The Board also is responsible for collecting and standardizing names of places outside the United States to meet official U.S. needs. In these functions, the Board collaborates with national and international organizations. This fact sheet, however, deals with commemorative naming only in the United States.
The following five principles have been followed by the Board in national geographic name standardization for over 100 years:

1. The Roman alphabet is used as normally employed in the English language.

2. Precedence is given to names in local usage.

3. Names established by Act of Congress are official by law.

4. Names of political subdivisions, bounded areas of administration, structures, and establishments - as determined by the appropriate, responsible public or private authorities - normally are recognized as official.

5. One name, one spelling, and one application are authorized for each geographic entity. 
In addition, the Board's actions are guided by the following policies:

1. Derogatory names or names that cause confusion are unacceptable.

2. Duplicate names within a local political jurisdiction are not normally approved.

3. Within wilderness areas, unnamed features remain unnamed, unless a name is required for purposes of safety, education, or area administration.

4. Ownership of land is not sufficient grounds to justify Board approval of a commemorative name.

\section{Commemorative Naming Policy}

In the United States, thousands of people have contributed and will continue to contribute to society in many different ways. Many deserve to be honored. Such recognition can take many forms, including scholarships or charitable funds established in an individual's name, a commemorative plaque, or a donation to support some aspect of the individual's education, career, or recreational interests. Commemorative naming of geographic features is but one of many options to consider when memorializing individuals and their accomplishments.

Although the Board realizes that such recognition may be desirable, it is neither possible nor appropriate to approve every commemorative naming proposal submitted. To evaluate objectively the increasing number of commemorative requests received each year, the Board uses the following principles, policies, and procedures in making decisions:

Section 1-The U.S. Board on Geographic Names will consider proposals for assignment of the names or nicknames of deceased persons to geographic features in the United States and areas under the jurisdiction of the United States. The Board will not consider names that commemorate or may be construed to commemorate living persons. In addition, a person must be deceased at least 5 years before a commemorative proposal will be docketed for consideration.

Section 2-The person being honored by the naming should either have had a direct long-term association with the feature or have made a significant contribution to the area or State in which it is located.

Section 3-A proposal commemorating an individual with an outstanding national or international reputation will be considered even if the person was not directly associated with the geographic feature.

Section 4-All commemorative name proposals must meet the same basic criteria required of any other name proposal.

\section{Guidelines}

A proposal to commemorate an individual must contain evidence of local support for the name and its application. Such evidence can be letters from local residents and administrative agency personnel and petitions containing signatures of local citizens.

Proposers must petition their State names authority, as well as the Federal Board. In States with no official State names authority, approval must be obtained from local governing bodies, such as the county commissioners, supervisors, or town selectmen.

The Board defines a "significant contribution" as an action(s) by an individual to protect, restore, enhance, or maintain a feature that produces substantial, longterm improvements.

The Board defines "direct long-term association" as 20 years or more of continued or periodic service to a feature. However, some proposals that do not meet this 20-year test can still be approved under special circumstances. Usually, an association of a significantly shorter time period requires strong local agreement on the importance of that association. This agreement may take the form of current local usage of the name being proposed or a general sense that the history of the area has been enriched through the individual's involvement with the feature.

A person's death on or at a feature, such as in a mountaineering accident or plane crash, or the ownership of land or the feature, does not normally meet the "direct association" criterion. Ultimately, the decision on whether a proposal meets the "direct long-term association" or "significant contribution" criterion rests solely with the Board.

\section{Procedures For Submitting and Reviewing a Proposal}

\section{Proposer should submit the name proposal with proper documentation.}

2. Proposer should obtain evidence of local support for the proposed name in the form of letters and petitions.

3. The Board, working through State and local governing bodies, determines whether the name is in the public interest on the basis of appropriateness, acceptability, and need.

\section{For More Information}

For more information on commemorative naming, contact:

Executive Secretary

Domestic Names Committee

U.S. Board on Geographic Names

U.S. Geological Survey

523 National Center

Reston, VA 20192

Phone: 703-648-4544

Fax: 703-648-4549

The Board urges proposers to consider carefully an individual's association with the identified feature and evaluate this relationship on the basis of the policies of the Board.

Because of these policy constraints on naming geographic features, commemorative name proposals often cannot be approved by the Board. When a proposal is disapproved, it is usually because of a failure to meet policy criteria rather than being a negative reflection on an individual's achievements.

For information on other USGS products and services, call 1-888-ASK-USGS, use the Ask.USGS fax service, which is available 24 hours a day at 703-648-4888, or visit the general interest publications Web site on mapping, geography, and related topics at http://mapping.usgs.gov/ www/products/mappubs.html.

Please visit the USGS home page at http://www.usgs.gov/. 